\title{
A NOÇÃO DE CULTURA EM APROPRIAÇÃO CULTURAL
}

WILLIAM, Rodney. Apropriação cultural. São Paulo, SP: Pólen, 2019.

O livro Apropriação Cultural é o sétimo volume da coleção Feminismos Plurais, coordenada por Djamila Ribeiro, o que o coloca em uma série que se interliga e em um contexto autodefinido como o de "disseminação de conteúdo crítico produzido por pessoas negras, sobretudo mulheres, a preço acessível e linguagem didática, como forma de construir instrumentais para compreender a realidade e debates profundos no país" (FEMINISMOS PLURAIS, 2021). Esta resenha atende ao chamado da coleção - ainda que este seja um implícito do resenhista... - de debate profundo e de formulação de conteúdo crítico.

Uma sinopse simples do livro de Rodney William, doutor em Ciências Sociais e babalorixá, o definiria como a explicitação do conceito de <apropriação cultural> a partir de uma perspectiva histórico-cultural que critica o colonialismo, a aculturação e o aniquilamento dos costumes das/os afrodescendentes, submetidas/os ao longo regime escravocrata brasileiro. $\mathrm{O}$ autor define o conceito de que trata como "um mecanismo de opressão por meio do qual um grupo dominante se apodera de uma cultura inferiorizada, esvaziando de significados suas produções, costumes, tradições e demais elementos" (WILLIAM, 2019, p. 29).

Assim, em linhas gerais, a apropriação cultural ocorreria quando elementos específicos de uma cultura são adotados fora de seu contexto e sem os seus significados particulares. E a apropriação poderia ocorrer em vários âmbitos: nas artes, na linguagem, na religiosidade etc.

Rodney William trata a <apropriação cultural> como um fenômeno que está no contexto do capitalismo e da globalização. Por um lado, a cultura seria transformada em mercadoria pela indústria cultural, que a esvaziaria de outros significados e lhe daria um sentido comercial. Por outro lado, a globalização teria acelerado o contato entre as diferentes culturas do mundo, por meio do avanço das tecnologias, tanto quanto por meio das migrações e diásporas. Neste quadro, surgiriam os grupos vinculados às identidades culturais, fazendo

\footnotetext{
${ }^{1}$ Professor do curso de Letras da Universidade Estadual de Goiás (UEG/Campus Cora Coralina) e doutorando em Estudos da Literatura na Universidade do Estado do Rio de Janeiro (PPGL-UERJ). ORCID http://orcid.org/0000-0003-0058-8935 .E-mail: cesar.casella@gmail.com
} 
política e pressão, reivindicando os seus direitos a partir do resgate de práticas e artefatos tradicionais, de sua ancestralidade.

A obra de William, como se vê, está em linha com um programa de resistência cultural que é desenvolvido e levado adiante por um grupo identitário, pelo qual se visa o resgate dos elementos tidos como originários das populações africanas e/ou dos antepassados escravizados no Brasil, ressignificando-os e direcionando-os ao enfrentamento do racismo estrutural da sociedade brasileira contemporânea.

Desta forma, é importante para a argumentação do autor que se afaste quaisquer acusações de purismo cultural na questão da <apropriação cultural>, ou seja, o conceito não deveria ser entendido como uma forma de limitar o uso de artefatos e elementos culturais exclusivamente à cultura que os criou. $\mathrm{O}$ contexto de compreensão deve ser o da relação que se estabeleceu entre os grupos hegemônicos e os grupos marginalizados, do etnocentrismo, do preconceito e o da exclusão. Similarmente, o conceito não deve ser tratado no âmbito das individualidades, mas sim como uma questão estrutural e vinculada à sociedade. Este enquadramento visa garantir que a <apropriação cultural> seja vista como uma nova faceta da dominação histórica presente no Brasil.

Embora William, no item Pode ou não pode? (2019, p. 69-98), efetivamente discuta e normatize questões relativas ao uso de turbantes, tranças, dreads, elementos religiosos e étnicos, bem como critique a presença da "branquitude" nos terreiros, a "capoeira gospel" e o "bolinho de Jesus", ele pretende que o mais importante "é dar elementos para que se compreendam as estruturas do racismo e todos os dispositivos do colonialismo e do capitalismo" (WILLIAM, 2019, p. 71).

O ponto que leva a esta resenha é que o conceito de <cultura> que subsidia a noção de <apropriação cultural> proposta por Rodney William, visto como derivado de uma certa formação discursiva $\left(\mathrm{FD}^{2}\right)$, traz uma questão complexa: o modo como William vê a <cultura> é o único modo possível? Além disto, mesmo dentro da perspectiva antropológica de William, uma outra questão parece interessante: não haveria a possibilidade das teorias linguísticas interpelarem a discussão sobre a leitura e a interpretação da <cultura>?

É no item $O$ que é cultura? que William busca delimitar um conceito de cultura que serviria de fio condutor na compreensão da <apropriação cultural>. Apesar de citar Kabengele

2 Entendendo-se a FD, algo simplificadamente, como "todo sistema de regras que funda a unidade de um conjunto de enunciados sócio-historicamente circunscrito" (MAINGUENEAU, 1998, p. 68). Como ressalta Maingueneau (1998), o termo é plástico e de difícil manejo, sendo empregado, na análise, "sobretudo para os posicionamentos <ideológicos> marcados; fala-se também, mais facilmente, de formação discursiva para os discursos (políticos, religiosos...) que estão em concorrência num campo discursivo (...)” (p. 69). 
Munanga e Franz Fanon, no início de sua argumentação, William situa a sua noção de <cultura> a partir do trabalho de Geertz, que a delimita como algo essencialmente semiótico, como algo que deriva das teias de significados, e das análises, que o próprio homem tece sobre si mesmo (WILLIAM, 2019, p. 17).

Trata-se, então, de uma antropologia - e, por óbvio, de uma explicação da cultura que busca interpretar, que procura significados e não leis gerais científicas. William aproxima essa noção de cultura (a <teia de significados>) ao conceito nagô revelado pelo mito de Exu (a <troca>), vendo-a como essencial na compreensão da <apropriação cultural>, unidas pelo "grande aumento no interesse pelo papel das formas simbólicas na vida humana" (2019, p. 17). Esta definição de cultura também teria valor por manter a análise das formas simbólicas estreitamente ligada aos acontecimentos sociais e às ocasiões concretas.

A <cultura>, a partir de Munanga, é colocada dentro do contexto de crítica aos mecanismos de manutenção da dominação, no âmbito da globalização capitalista neoliberal. Relaciona-se <cultura> à preservação da natureza e, na sequência, aos valores ancestrais africanos. Assim, tudo somado, William (2019) estabelece <cultura>, amplamente, como:

\footnotetext{
um conjunto de características humanas que não são inatas e abarcam muito mais do que aspectos visíveis, concretos. O jeito de andar, falar e pensar; de se vestir, se portar e sentir; a fé, a visão de mundo, as relações; as criações, as instituições e os valores de um grupo; a arte e o saber. Em síntese, cultura pode ser compreendida sob vários ângulos: ideias, crenças, valores, normas, atitudes, padrões, abstrações, instituições, técnicas etc. Tudo isso, inserido na cultura de um povo, possui significados e história. (p. 18)
}

Agregada a esta definição, já ampla e algo retroalimentada, está o pressuposto de que ao nomear (coisas, seres, sentimentos, tradições, crenças etc.), como faz Exu, "um povo atribui valores e juízos que constituem um sistema de ideias bem próprio e pode ser entendido como uma resposta humana que ajuda a organizar a vida em sociedade" (WILLIAM, 2019, p. 18), o qual leva ao corolário de que todas as sociedades humanas produzem culturas.

Ao término desta extensa delimitação, e partindo de uma menção - infelizmente não referenciada... - de que Geertz sugeria que a cultura deve ser vista como um conjunto de mecanismos de controle para governar o comportamento, pois os símbolos existentes na sociedade são usados para impor significado às experiências, William acresce a afirmação de que "a cultura determina o modo como nascemos, o que comemos, como falamos e como nos movemos" (2019, p. 19). Do que se depreende algo como: as sociedades humanas produzem culturas que controlam os indivíduos dentro das sociedades humanas. 


\section{Linguagens - Revista de Letras, Artes e Comunicação - ISSN 1981- 9943 \\ Blumenau, v. 15, n. 2, p. 189-194, maio./ago. 2021.}

Retornando ao questionamento sobre se o modo como William vê a <cultura> é o único possível, a abordagem discursiva leva a pensar que diferentes FDs - já que cada sistema de regras gera uma unidade diferente para um conjunto de enunciados circunscritos sócio e historicamente... - desembocam em diferentes discursos. Dito de outro modo, a posição que vê a <cultura> como algo a ser interpretado, a partir de dados e fatos, é uma das FDs que informam a Antropologia e gera certo discurso. Mas não é a única FD que atua neste campo discursivo. Parece possível - e interessante - mostrar que há um debate na Antropologia entre as perspectivas da cultura como interpretação e da cultura como invenção.

Neste sentido, é possível dar notícia, ainda que sucinta, do debate contemporâneo sobre <cultura> na Antropologia. Flávio Ferreira (2012) escreve um artigo em que apresenta um histórico do termo <cultura> e reflete sobre as implicações da transformação deste termo em conceito para a Antropologia. O parti pris da reflexão é o de que, na antropologia contemporânea, não se pode refletir sobre <cultura> sem levar em conta a dicotomia que está na base da disciplina:

Cultura como fato, como aquilo que realmente existe e que é real. A cultura preexiste para o pesquisador, é autônoma e compõe a realidade social dos indivíduos; e Cultura como invenção, criada ou construída no campo da ciência. A cultura só existe a partir do momento que começa a se pensar sobre ela. (FERREIRA, 2012, p. 133)

Vê-se, então, duas FDs que concorreriam na Antropologia, gerando duas formas diferentes de compreender <cultura> e uma crise nos modelos explicativos desta disciplina. Lembrando que é nos Estados Unidos que surge o debate, Flávio Ferreira explica que Clifford Geertz insere a nova perspectiva da <cultura> como sistema de símbolos, expandindo-a e vendo-a como um sistema independente e autossustentável. É desta perspectiva que "o comportamento humano é visto como ação simbólica” (FERREIRA, 2012, p. 140).

Em outra perspectiva estaria o trabalho de Roy Wagner, que lida com a ideia de invenção, constituída reflexivamente no campo da ciência, tratando-a "como criação exógena aos grupos estudados" e afirmando "o caráter simbólico das culturas com uma capacidade inerente à mudança, à inovação e à reflexividade” (FERREIRA, 2012, p. 141).

Nesta avaliação, a noção de cultura de Wagner é vista como "propriamente cultural, porque se constitui a partir da explicitação de que essa noção é um artefato cultural" (FERREIRA, 2012, p. 142), isto é, ela é produto de uma perspectiva cultural específica, a do antropólogo ou a de qualquer outro que se debruce sobre a cultura. A Antropologia operaria inventando a cultura, enquanto uma chave conceitual, não a encontrando ou a descobrindo. 
Na proposta de Wagner haveria "uma empreitada contra a naturalização" (FERREIRA, 2012, p. 142), uma busca por desnaturalizar o tratamento da cultura e por fugir da essencialização, além de um reforço na importância de não tipologizar as sociedades.

Esta coocorrência de FDs na Antropologia também pode ser vista na resenha de Márcio Goldman (2011) para A invenção da cultura, de Roy Wagner. Ele lembra que a obra de Wagner é da mesma época de A interpretação das culturas, de Geertz, e Cultura e razão prática, de Marshall Sahlins (1975, 1973 e 1976 respectivamente). A circulação destas obras no Brasil, entretanto, é completamente diferente: enquanto o livro de Wagner só foi traduzido em 2010, os outros dois estão na bibliografia de quase todos os programas de curso de teoria antropológica.

Ao adotar um conceito de cultura advindo da antropologia interpretativa, portanto, Rodney William está se filiando a uma certa FD, a um certo posicionamento discursivo e a uma certa ideologia. No entanto, esta FD não é a única que informa a Antropologia e, indo um pouco mais além, não é a única FD que informa o conceito de <cultura>, bastando lembrar que a posição ideológica do marxismo provê uma outra FD que gera um outro discurso sobre cultura. Resta notar - ainda que aqui não se possa desdobrar o postulado... - que diferentes concepções sobre <cultura> ocasionam diferentes compreensões de <apropriação cultural>.

A outra questão enunciada anteriormente, sobre a possibilidade das teorias linguísticas interpelarem a discussão sobre a leitura e a interpretação da 〈cultura〉, dentro mesmo do quadro de uma Antropologia interpretativa, abre um longo caminho que aqui será apenas delineado em termos gerais dos Estudos da Linguagem.

Como se sabe, tratar os sentidos - os significados, a significação etc., a depender da vertente de filiação... - é a base de muitas áreas dos Estudos da Linguagem, quer se focalize os emissores, os textos ou os receptores. Assim, quando se trata de interpretação, muitos dos problemas que a Análise do Discurso encontra e discute - bem como o faz a Linguística Textual, a Pragmática etc., salvaguardadas as diferenças teóricas - podem ser transladados para a discussão em tela: Se a <cultura> é da ordem das semioses, se ela é um <texto> a ser interpretado, não há o perigo de superinterpretações (ou então de sub-interpretações)? Quem arbitra a interpretação? Qual é o limite da interpretação da <cultura> como <texto>?

Como compreender, a partir de diferentes vertentes da Linguística - a escolher: diante da noção saussuriana de arbitrariedade do signo; diante de uma Semântica que não é referencialista; diante dos postulados de performatividade da Pragmática; diante do postulado central da Análise do Discurso de que o sujeito não está na origem do sentido... - a 
capacidade humana de nomear coisas, de atribuir significados/valores e de organizar a vida em sociedade a partir disto, em que William (2019, p. 18) confia?

As questões específicas desta resenha poderiam apontar para uma outra, bem mais geral, a saber: o ser humano é um fato? A famosa página final de As palavras e as coisas ajuda na reflexão arqueológica sobre a constituição do 〈homem> e da <cultura> pela Antropologia, se esta puder ser pensada como integrante das Ciências Humanas:

Uma coisa em todo caso é certa: é que o homem não é o mais velho problema nem o mais constante que se tenha colocado ao saber humano. Tomando uma cronologia relativamente curta e um recorte geográfico restrito - a cultura europeia desde o século XVI - pode-se estar seguro de que o homem é uma invenção recente. Não foi em torno dele e de seus segredos que, por muito tempo, obscuramente, o saber rondou. De fato, dentre todas as mutações que afetaram o saber das coisas e de sua ordem, o saber das identidades, das diferenças, dos caracteres, das equivalências, das palavras - em suma, em meio a todos os episódios dessa profunda história do Mesmo - somente um, aquele que começou há um século e meio e que talvez esteja em via de se encerrar, deixou aparecer a figura do homem. (FOUCAULT, 1999 [1966], p. 536)

\section{REFERÊNCIAS}

FERREIRA, F. R. F. A “morte” da cultura? Do modelo clássico ao debate contemporâneo. Revista Inter Legere, n. 10, pp. 132-148, Jan./Jun. 2012.

FEMINISMOS PLURAIS. O que é a coleção? In: FEMINISMOS PLURAIS. Sobre a coleção. Feminismos Plurais. 2021. Disponível em: https://feminismosplurais.com.br/sobre/. Acesso em: 19/02/2021.

FOUCAULT, Michel. As palavras e as coisas: uma arqueologia das Ciências Humanas. 8 ed. Tradução de Salma Tannus Muchail. São Paulo/SP: Martins Fontes, 1999.

GOLDMAN, M. O fim da Antropologia. Novos estudos CEBRAP, n. 89, pp. 195-211, São Paulo/SP, Mar. 2011.

MAINGUENEAU, Dominique. Termos-chave da análise do discurso. Tradução de Márcio Venício Barbosa e Maria Emília Amarante Torres Lima. Belo Horizonte/MG: Ed. UFMG, 1998.

WILliAM, Rodney. Apropriação cultural. São Paulo/SP: Pólen, 2019. (Coleção Feminismos Plurais) 